\title{
FOOD POLICY AND PLANNING IN HUNGRY COUNTRIES
}

$\mathrm{E}$ STIMATES of the proportion of the world's population that is hungry for all, or the greater part, of the year vary from about 20 to about 70 per cent. The main reasons for this very large margin of uncertainty are two. In the first place, reliable food consumption surveys, far from easy in highly developed countries, are, in most of the underdeveloped countries, extraordinarily difficult to carry out, and the rosults may be particularly misleading where a major part of a population is engaged in agriculture. In the second place, existing, welldefinod standards for adequate nutrition applicable to Western populations have to be interpreted with great care in relation to populations, the individuals of which differ in physical size from Western individuals, or where there is a marked different age distribution, or where many of the individuals carry out quite different types of physical work under different environmental conditions from those in the technologically advanced countries. Nevertheless, to any but the most fleeting Western visitor, it is abundantly obvious that undernutrition is widespread in Far Eastern countries, and malnutrition, especially among young children, is particularly marked.

Pursuing his inquiries further, the observant Western visitor may find that in some at least of these countries the responsible authorities, while cognisant in a distant way that hunger, or even seasonal near-starvation, may afflict a substantial percentage of the people under their charge, scarcely know where to begin in an endeavour to raise nutritional standards.

The fourth Food and Agriculture Organization Regional Conference for Asia and the Far East (1958), recognizing "that the technical issues involved in food policies and planning need to be elarified early from the nutritional angle on a regional basis for the guidance of the governments", recommended to the Director-General of the Organization that a meeting should be convened as soon as possible to consider "the various aspects of the problem of linking the nutritional needs of the people with national policies and plans relating to food and agriculture". The meoting was duly held in Bangkok, Thailand, in June 1960, and its recently published report gives an account of its proceedings and recommendations*. The countries represented at the meeting were India, Thailand, Philippines, Ceylon, Indonesia and Taiwan. Present also were representatives from the World Health Organization, the United Nations International Children's Emergency Fund, the Economic Commission for Asia and the Far East, and a strong group from the Food and Agricultural Organization.

For any country intending to introduce a national policy for nutritional improvemənt, the essential requirement is reliable information on the actual situation, quantitative and qualitative, of both food production and food consumption in the various districts and among the different socio-economic groups in that country. The first chapter of the report endeavours to make the beginnings of an appraisal of food consumption per head per day, both

* Report of the Technical Meeting on Nutrition in Food Policy and Planning in Asia and the Far East. FAO, Rome, 1961, pp. 49. H.M.S.O., $2 s, 6 d$. for the countries represented at the meeting, and also for some of the unrepresented countries, Japan, Korea, Burma and Malaya. The conclusion is reached that "the average levels of food consumption do not appear to be satisfactory", a statement which seems to me, who has seen conditions in part of the Far Fast, to provide a classical example of meiosis. In fact, if the figures quoted in the report for quantitative food consumption are reliable, the average calorie intake of all except one of these countries is highly unsatisfactory; further, the paragraphs in the same chapter reporting the widespread incidence of deficiency diseases - among which beriberi is reported to be still common in the Philippines, Burma, VietNam and North Thailand--indicate that qualitatively also, many of the Far Eastern diets are seriously inadequate. Another comfortless statement in this chapter is that except in Japan (where per caput fish supplios have more than doubled since the War. and where milk supplies aro rapidly increasing) the intake of animal protein has declined in these countries in recent years. The report points out that "elinically-evident cases of malnutrition represent only a fraction of their provalence. Cases without frank manifestation but with impaired vital functions . . . are usually disregarded, with the result that the magnitude of the problem is hardly realized".

The establishment of food consumption targets, both long-term and medium-term, is dealt with in the second chapter. Among the general principles outlined, one is of especial significance that in planning for increased food supplies, improved indigenous production should be the basis, a fact which appears still to be only partially recognized in several of the Far Eastern countries. As regards medium-term objectives, a compromise between what is nutritionally desirable and what is economic ally feasible is recognized as inevitable, though what is economically feasible, in a sovoreign country at least, is a matter which is to a large extent under 'indigenous' control.

The third chapter is mainly concerned with improvement in nutrition through food policies and plans. The complex of interrelated factors influencing food consumption and nutrition varies so much from one country to another, or even from one region to another within the same country, that generalizations made in this chapter tend to be so broad as to become truisms. Thus, few can doubt the scarcely epochmaking statement made in the report that the most important economic factor which determines what people eat is their purchasing power. The equally important factors, in several Eastern countries, of religious prohibitions and traditional taboos, which still add gratuitous handicaps to the nutritional burdens at present borne by the humbler citizens in these countries, or bound up as those handicaps are with the difficulties, particularly among the illiterate, of "motivation towards change", receive little emphasis.

The usual, unexceptional recommendations are made-better education in nutrition, homo economics, and dietetics, increase in the number and influence of food and nutrition organizations, the neod to train individuals who can correlate nutritional needs with agricultural food production from land 
or sea. Fow of these individuals exist in the hungry countries at present.

In the fourth and final chapter the need for improved staffing, equipment, status and influence of nutrition research centres in the Far Eastern countries is stressed, and the establishment in each country of a strong committee representing health, agriculture, education, economics and social welfare, capable both of advising the Government and stimulating action along effective lines, is recommended.

Clearly visible through all the cautious phraseology of this report is the general agreement that a sig. nificant improvement in most of the Far Eastern countries depends on influencing governments to give indigenous efforts toward the achievement of such improvement both high priority and adequate funds. These efforts would include the far eloser correlation of agricultural, economic and nutritional policy, and the training forthwith of adequate numbers of indigenous technologists in these fields.

Truly, the improvement of national diets in the hungry countries is a problem which must depend for its solution on indigenous effort, with, especially in the early stages, specialist assistance, 'know-how' and finance from United Nations agencies and other outside sources. The technical knowledge required is already available in the world; if it is adequately applied, very few indeed of the hungry countries need remain so.

\section{TEACHING BIOLOGY IN AMERICAN HIGH SCHOOLS}

$\mathrm{E}^{\mathrm{A}}$ ARLY in 1959 the American Institute of Biological Sciences, an association of forty-seven societies with an aggregate membership of 84,000 , set up the Biological Sciences Curriculum Study under the chairmanship of Prof. Bentley Glass of the Johns Hopkins University. Arnold B. Grobham, of the University of Florida, agreed to serve as full-time director of the project, and space for a permanent headquarters was obtained on the campus of the University of Colorado. With financial support assured by the National Science Foundation, the aim of the Biological Sciences Curriculum Study was to examine the defects of present biology teaching at all levels and the provision of specific programmes and materials to bring biology curricula up to date and to focus them more sharply on what a consensus would hold to be the major objectives of biology teaching.

At the outset, it was decided to begin by tackling the problem of biology at the high-school level. Although the defects of biology teaching in the elementary school or in the colleges may be fully as great, it is in the secondary schools that greatest choice of occupation is made; it is here that one finds the last opportunity to teach the sciences, and specifically biology, to nearly every future citizen. Clearly, much of the difficulty in interesting students in the study of biology at more advanced levels derives from the failure of high-school biology teaching to awaken the interest commensurate with its importance.

A steering committee was formed, comprising some thirty persons, who included not only college and university biologists recognized for their research as well as their interest in education but also highschool teachers of biology, writers of text-books and teachers' hand-books, and high-school administrators. During the course of the first year, the steering com. mittee formulated a general plan of procedure and discussed the problems posed by the existence of an antiquated biology curriculum in the secondary schools. There was general agreement on several key points. Some of the findings of the committee are outlined in a recent issue of the American Scientist (49, No. 4; December 1961).

The biological sciences are at present advancing at so rapid a rate as to double the amount of significant knowledge every 10-15 years. While this fact makes it imperative to revise courses and methods of teaching at more and more frequent intervals, it also makes it increasingly impossible to 'cover' in any course all that is significant and that a general citizen might profitably know, Most high-school text-book: are twenty years behind the advancing front of knowledge, and in somo very significant matters. because of social or religious opposition, fully a century in arrears. Appropriate scientific treatment must be accorded such 'controversial' subjects as organic evolution, the nature of the individual and racial differences, sex, reproduction in the human species, and the problems of population growth and control.

Even worse than the failure to keep biology for the class-room up to date is the prevalent fault of teaching the life sciences (and indeed all othors) as constituting essentially a body of established 'true' information, knit by concepts and laws of nature assumed to be unalterable and prescriptive. That observations are always limited, that laws of Nature are mere summations of experience, and that science consequently is for ever adding new observations, modifying its concepts, and refining or replacing its laws of Nature, are principles honoured in the breach. The conception of science as a body of methods of inquiry - involving accurate and confirmable observations, quantitative treatment of data, and controlled experimentation-gets lip service, but rarely, if ever, enters into the experience of the student at the highschool level. In particular, so-called laboratory work has become a travesty of genuine scientific activity.

It is the essence of the life sciences that they are diverse in point of view and methodology. In consequence, there is no single best way to organize a biology course. There is a vast difference botween the analytical, physico-chemical approach of the biochemist or biophysicist and the organismal approach of the student of behaviour and the supraorganismal view of the ecologist who must deal with communities and ecosystems. It is both valid and necessary to explore a variety of ways of approaching and organizing the subject-matter of biology.

Whatever the approach and whatever the organization, the essential character of scientific activity and the great biological themes must permeate the treatment. On one hand, the nature of science as an increasingly important element of human history must be stressed. On the other, the warp and woof of the treatment of the subject-matter must consist of the great biological themes such as the interdependence of structure and function, regulation and homeostasis, the genetic continuity of life, its evolution, diversity of type bound up with unity of pattern, and the relation of organism to environment. These 